\title{
Attributing Greenland Warming Patterns to Regional Arctic Sea Ice Loss
}

Pedersen, Rasmus A.; Christensen, Jens Hesselbjerg

Published in:

Geophysical Research Letters

DOI:

10.1029/2019GL083828

Publication date:

2019

Document version

Publisher's PDF, also known as Version of record

Citation for published version (APA):

Pedersen, R. A., \& Christensen, J. H. (2019). Attributing Greenland Warming Patterns to Regional Arctic Sea Ice Loss. Geophysical Research Letters, 46(17-18), 10495-10503. https://doi.org/10.1029/2019GL083828 


\section{Geophysical Research Letters}

\author{
RESEARCH LETTER \\ 10.1029/2019GL083828 \\ Key Points: \\ - Warming in coastal parts of \\ Greenland can in part be attributed \\ to nearby sea ice loss \\ - Only a limited part of the warming \\ on central Greenland can be \\ attributed to sea ice loss \\ - Sea ice loss in more remote regions \\ has a minor impact on Greenland \\ warming
}

Supporting Information:

- Supporting Information S1

Correspondence to:

R. A. Pedersen,

rap@dmi.dk

Citation:

Pedersen, R. A., \& Christensen, J. H. (2019). Attributing Greenland warming patterns to regional Arctic sea ice loss. Geophysical Research Letters, 46, 10,495-10,503. https://doi.org/10.1029/ 2019GL083828

Received 22 MAY 2019 Accepted 18 AUG 2019 Accepted article online 21 AUG 2019 Published online 2 SEP 2019

(C)2019. American Geophysical Union. All Rights Reserved.

\section{Attributing Greenland Warming Patterns to Regional Arctic Sea Ice Loss}

\author{
Rasmus A. Pedersen ${ }^{1}$ (D) and Jens Hesselbjerg Christensen ${ }^{1,2,3}$ i \\ ${ }^{1}$ Danish Meteorological Institute, Copenhagen, Denmark, ${ }^{2}$ Niels Bohr Institute, University of Copenhagen, Copenhagen, \\ Denmark, ${ }^{3}$ NORCE, Norwegian Research Centre, Bergen, Norway
}

\begin{abstract}
Observed and model-projected sea ice loss enhances warming in the Arctic. We investigate to what extent warming on Greenland can be attributed to changes in the sea ice cover in different parts of the Arctic. Using Climate Model Intercomparison Project phase 5 model projections of the future, we perform multilinear regressions to separate the simulated warming on Greenland in two parts; one following global warming and one following regional sea ice changes. This reveals the magnitude and spatial pattern of warming on Greenland, which can be attributed to sea ice loss in different Arctic regions. The results indicate that the impact of sea ice loss is largely confined to the coastal parts of Greenland. We find the strongest links to sea ice loss in adjacent regions; remote regions only have a limited impact. Overall, warming attributable to sea ice variability is a minor contribution but can be a dominant signal locally in coastal regions.
\end{abstract}

Plain Language Summary The observed decline of the Arctic sea ice cover is projected to continue with continued global warming. Sea ice loss contributes to amplified warming in the Arctic region, which could increase melting on the Greenland Ice Sheet and thereby contribute to global sea level rise. Here, we study the long-term warming impact from sea ice loss using data from 10 climate models covering the period 1850-2300. Our aim is to isolate the warming contribution from sea ice loss and study how it varies across Greenland for sea ice loss in different parts of the Arctic. The results indicate that sea ice loss occurring near Greenland has a warming impact along the adjacent coasts but only a limited impact on the central, more elevated ice sheet. Sea ice loss occurring in more remote parts of the Arctic has no substantial impact on Greenland. Finally, our analysis suggests that sea ice loss provides a minor contribution to Greenland warming overall, but it can be a dominant effect locally in coastal areas.

\section{Introduction}

The loss of Arctic sea ice observed over the satellite era (i.e., since 1979) is projected to continue due to global warming. This has serious consequences not limited to but of particular relevance within the Arctic. This includes possible linkages of sea ice loss to midlatitude weather patterns (Overland et al., 2016; Vihma, 2014), changing habitats for flora and fauna and changing prospects for societies and activities in the high north (Larsen et al., 2014; Meier et al., 2014), and continued amplified warming of the Arctic (Dai et al., 2019; Pithan \& Mauritsen, 2014; Serreze \& Barry, 2011). The latter includes enhanced warming over the Greenland Ice Sheet (GrIS), which implies potentially accelerating mass loss contributing to global sea level rise-recent Arctic sea ice loss coincides with increasing runoff from the ice sheet (Mouginot et al., 2019; Trusel et al., 2018). Here, we address the sensitivity of the GrIS to Arctic sea ice evolution in the prevailing and future climate conditions. Assessing this sensitivity and its future development is challenging. For example, climate model simulations differ widely in their timing of the loss of Arctic sea ice for a given trajectory of anthropogenic $\mathrm{CO}_{2}$ emissions. Within the Climate Model Intercomparison Project phase 5 (CMIP5; Taylor et al., 2012), some models project a near-ice-free Arctic at the annual minimum as early as 2030, while other models retain a year-round sea ice cover into the next century (Hezel et al., 2014; Massonnet et al., 2012; Wang \& Overland, 2012), even for an external forcing based on largely undamped anthropogenic $\mathrm{CO}_{2}$ emissions (the Representative Concentration Pathway scenario RCP8.5; van Vuuren et al., 2011).

Previous work (Notz \& Stroeve, 2016) has shown that Arctic sea ice loss almost linearly follows $\mathrm{CO}_{2}$ emissions and hence global warming. Here, we investigate if warming on Greenland follows the global trend, or if (some of) the change can be attributed to more local-scale variations in the sea ice cover. Despite the 
expectation that sea ice loss is a key contributor to amplified Arctic warming (Dai et al., 2019; Screen \& Simmonds, 2010; Serreze \& Barry, 2011), the still short observational record of the Arctic sea ice cover change makes it challenging to show direct links between sea ice loss and warming over Greenland. Previous studies have focused on process-based attribution using lagged correlations to trace the sequence of events from sea ice reduction to increased warming or melt on the ice sheet (e.g., Ballinger et al., 2018; Rennermalm et al., 2009; Stroeve et al., 2017). Here, we use a linear framework, aiming to separate the simulated warming in two contributions: one following the global warming trend and one following the Arctic sea ice conditions.

Motivated by the varying trends of and sensitivities to sea ice loss in different Arctic regions (Onarheim et al., 2018; Pedersen et al., 2016; Screen, 2017; Stroeve et al., 2012; Sun et al., 2015), we perform the analyses for contributions from separate regions of the Arctic. The regions are defined following Screen (2017), based on analyses of Arctic regions with covariability in the observed sea ice area trends (see also supporting information, Figure S1). Since projections of regional sea ice trends are highly model dependent, we employ this regional view in a future context; although we acknowledge that some of the regional changes may be codeveloping differently during the potential transition toward an ice-free Arctic Ocean.

Generally, sea ice loss can impact tropospheric temperatures via both thermodynamic and dynamic processes (e.g., Sun et al., 2015). The former describes heat release by turbulent and longwave surface fluxes (Serreze \& Barry, 2011), which can spread to adjacent areas through horizontal advection (Serreze et al., 2011), while the latter describes large-scale atmospheric circulation changes forced by sea ice loss (Vihma, 2014). Our approach does not identify the underlying mechanisms but implicitly includes both of these types of links between sea ice loss and warming on Greenland. The thermodynamic impact is more likely from oceanic regions close to Greenland, while linkage with more remote regions of sea ice loss likely requires a circulation response to cause substantial warming on Greenland. Idealized model studies indicate that ice loss near Greenland has a warming impact, while more remote ice loss has a negligible impact (Pedersen et al., 2016; Screen, 2017).

The warming impact of sea ice loss is largest during winter, when the ocean is warm relative to the atmosphere (Vihma, 2014). In summer, the ocean-atmosphere temperature gradient is small, and the excess energy from forcing and feedbacks will increase melt of any remaining snow and ice; hence, temperatures remain confined to the freezing point (Serreze et al., 2009). Consequently, winter warming may dominate the annual mean changes investigated here. While our focus is on long-term changes in annual means, we will briefly comment on the summertime patterns in section 3 .

\section{Data and Methods}

We base our analysis on the available CMIP5 simulations following the RCP8.5 emission scenario extended to year 2300 (Meinshausen et al., 2011) as this includes several examples of loss of the Arctic sea ice, even during winter. We have expanded the ensemble with an additional CMIP5 model, EC-Earth v.2.3 (Hazeleger et al., 2012, 2010; S. Yang, Danish Meteorological Institute, personal communication), giving a total ensemble of ten models (model details are presented in supporting information, Table S1).

The analysis is based on near-surface air temperature (2-m temperature) and fractional sea ice concentration from the model ensemble. The sea ice concentration is recalculated into total area (i.e., not sea ice extent but surface area covered by sea ice) by multiplying with the area of each grid cell. In order to identify the sensitivity to sea ice loss in different parts of the Arctic, we have separated the Arctic into 10 different regions obtained from Screen (2017), including for completeness the North Pole area (NP; not featured in Screen, 2017; see also supporting information, Figure S1).

We pose the question: in a long-term sense, can we attribute part of the warming over Greenland to sea ice changes occurring in different parts of the Arctic? Our approach is based on a multiple linear regression, expressing the temperature change in Greenland as a function of global temperature change and the state of the sea ice cover (i.e., the area change) using annual means of all three variables. For each model, in each grid cell on Greenland, we evaluate 


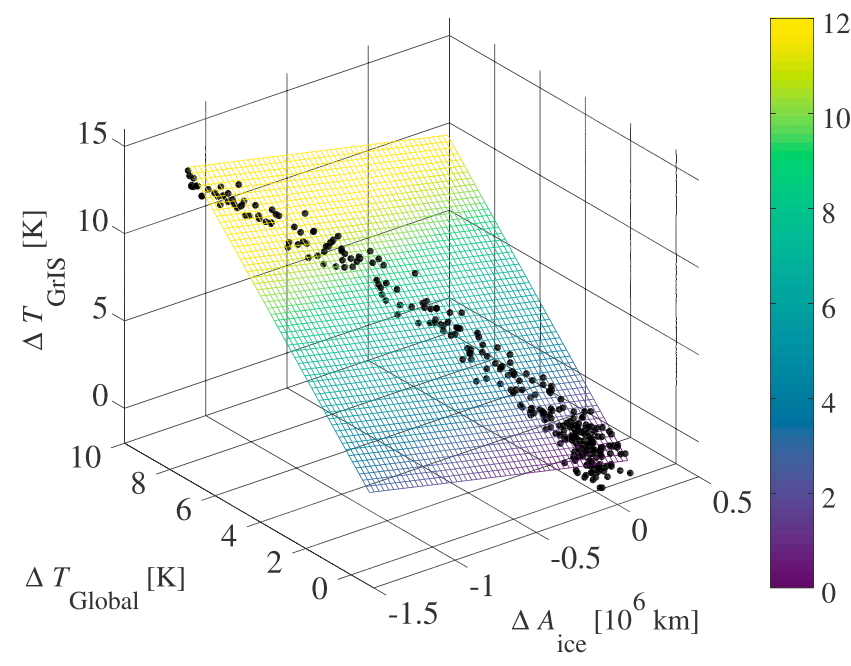

Figure 1. One example illustrating the multilinear regression finding the best fit plane expressing the warming in one grid cell on Greenland

$\left(\Delta T_{\mathrm{GrIS}}\right)$ as a function of global warming $\left(\Delta T_{\mathrm{Global}}\right)$ and regional sea ice area change $\left(\Delta A_{\text {ice }}\right)$. Black spheres indicate the annual mean values simulated by the model for each year from 1850 until the time of sea ice loss. The shading on the plane reflects $\Delta T_{\mathrm{GrIS}}$.

$$
\Delta T_{\mathrm{GrIS}}(t, x, y)=a_{\mathrm{T}} \Delta T_{\text {Global }}(t)+a_{\text {ice }} \Delta A_{\text {ice }}(t)+c
$$

where $\Delta T_{\mathrm{GrIS}}(t, x, y)$ is the change in near-surface air temperature at year $t$ at the location $(x, y), \Delta T_{\text {Global }}(t)$ is the global mean temperature change at year $t$, and $\Delta A_{\text {ice }}(t)$ is the change in sea ice area at year $t$ in a given region. The changes are all compared to the 1850-1899 average in the same variables (except for HadGEM where the reference period is 1860-1909 due to data availability). $a_{\mathrm{T}}[\mathrm{K} / \mathrm{K}], a_{\text {ice }}\left[\mathrm{K} / \mathrm{km}^{2}\right]$, and $c[\mathrm{~K}]$ are regression coefficients describing the best fit plane in the three-dimensional space of Greenland temperature, global temperature, and sea ice area changes (Figure 1).

The long-term view employed here is inspired by detection and attribution studies used, for example, in the context of the Intergovernmental Panel on Climate Change (Bindoff et al., 2013). It is meant to supplement process-based analyses (e.g., Rennermalm et al., 2009; Stroeve et al., 2017), attempting to reveal covariability between changes in different parts of Greenland and the state of the sea ice cover and the state of the global climate, respectively.

As we are investigating the impact of sea ice loss, the regression is restricted to the periods where sea ice remains in each analysis region. Consequently, the lengths of the time series in the regressions vary between regions and models. A region is here defined as ice free in the year when the annual mean sea ice area first is below $1 \%$ of the reference level.

In order to obtain confidence in the deduced relations, we enforce two criteria on each regression. The first criterion is a minimum requirement to the goodness of the fit, such that $R^{2}>0.9$, where $R$ is the coefficient of multiple determination (von Storch \& Zwiers, 2001), meaning that the fit explains more than $95 \%$ of the variance. The second criterion is based on a one-sample $t$ test comparing the sample distribution from each model to the hypothesized gradient in the linear relation, with the null hypothesis that the gradient is found randomly. Here, we require a confidence level of $p>0.95$.

Although the apparent link between global warming and Arctic sea ice loss is more involved when considering the individual sea ice regions, equation (1) could be modified to account for the impact of global warming on the ice loss, making the two contributing terms more clearly independent. We have repeated the analysis with an alternate approach replacing $\Delta A_{\text {ice }}$ with the so-called sea ice area residual change, calculated by subtracting the best fit linear regression between the regional sea ice change and the global warming. This alternate regression can be expressed as

$$
\Delta T_{\mathrm{GrIS}}(t, x, y)=a_{\mathrm{T}, \text { res }} \Delta T_{\mathrm{Global}}(t)+a_{\text {ice,res }}\left[\Delta A_{\text {ice }}(t)-\left(\frac{\partial \Delta A_{\text {ice }}}{\partial \Delta T_{\text {Global }}} \Delta T_{\text {Global }}(t)+b\right)\right]+c_{\text {res }}
$$

where $a_{T, \text { res }}, a_{\text {ice,res, }}$ and $c_{\text {res }}$ replace the regression constants $a_{\mathrm{T}}, a_{\text {ice, }}$ and $c$ from equation (1). Compared to equation (1), this approach represents a more conservative estimate of the sea ice impact. In the following section we present the results based on equation (1), illustrating an upper limit estimate of warming contribution from sea ice loss but discuss how these compare to the results from using equation (2).

We have termed equation (1) and (2) using changes instead of absolute values. This has the benefit of aligning the individual models, by adjusting for the reference temperature and sea ice cover at the beginning of the simulations. While our main assessment is based on robust changes across the individual models, this formulation allows us to supplement the analysis with attribution based on the complete, merged ensemble (ALLCMIP). The combined ensemble has been created by bilinear interpolation of all the models to a common grid, the coarsest grid in the ensemble (from the $\mathrm{BCC}$ model). The multilinear regressions (equations (1) and (2)) were then performed exactly as for each individual model, with the same requirements for the overall fit and the gradients. 


\section{Results and Discussion}

Under the extended RCP8.5 scenario, only two models in the ensemble retain an Arctic sea ice cover by the year 2300: GISSH and GISSR. Hezel et al. (2014) analyze Arctic sea ice in the CMIP5 models and highlight that the seasonal sea ice changes in these two models stand out from the ensemble: Both models lose the summer sea ice early (i.e., at low forcing and global warming) but retain winter sea ice throughout the simulations to year 2300. These two models have the lowest equilibrium climate sensitivity in our ensemble and the lowest global warming by 2300 (Table S1; Flato et al., 2013; Forster et al., 2013), which could explain why the winter sea ice remains. The earliest loss of sea ice, for the entire Arctic and by our metrics, is seen in HadGEM in 2122 (all models and their timing of sea ice loss are listed in Table S1).

For the remainder we will focus on the fraction of Greenland warming that can be attributed to regional sea ice changes, that is, the second term in equation (1) $a_{\text {ice }} \Delta A_{\text {ice }}(t)$. For each sea ice region and each model, the regression has returned an estimate for $a_{\text {ice }}$ in each model grid point on Greenland-provided that the statistical criteria were met. We quantify the warming contribution from this term by calculating a linearized warming estimate (LWE) based on equation (1) as the average contribution from the sea ice term in the linear relation compared to the simulated warming at the same point in space and time:

$$
\text { LWE }=\frac{\Delta T_{\mathrm{GrIS}, \text { linear,ice }}}{\Delta T_{\mathrm{GrIS}}}=\frac{1}{N} \sum_{t=0}^{N} \frac{a_{\mathrm{ice}} \Delta A_{\mathrm{ice}}(t)}{\Delta T_{\mathrm{GrIS}}(t)}
$$

Note that our method, which treats each sea ice region separately, means that the LWEs cannot be added to reflect the total impact of concurrent sea ice changes in different regions. As such, the actual value of the LWE represents an upper limit to the warming contribution, and our main focus is thus on the spatial pattern of the LWE. Maps of this relative warming measure are presented in Figures 2-4 for three highlighted regions: Barents-Kara Seas (BK; Figure 2), Canadian-Archipelago and Baffin Bay (CAB; Figure 3), and Greenland Sea (GS; Figure 4). The seven regions not highlighted here, that is, Beaufort and Chukchi Seas (BC), Bering Sea (BS), East Siberian and Laptev seas (ESL), Hudson Bay (HB), Labrador Sea (LS), Sea of Okhotsk (SO), and NP, only have smaller areas with significant regressions, and the magnitudes and spatial patterns of the estimated contributions are highly variable between the models (cf. Figures S2-S8).

Figure 2 reveals that sea ice loss in the BK region can be linked to a warming contribution along the northeast coast in all the models, albeit in varying strength and spatial extent. Except for one model (GISSH), the warming signal is confined to a thin belt along the coast at relatively low elevation. This pattern seems robust across the models, despite the very large range of regional sea ice projections; EC-Earth loses the BK sea ice at a global warming of $4.7^{\circ} \mathrm{C}$, while IPSL retains a BK ice cover until about $10^{\circ} \mathrm{C}$ warming. The ALLCMIP ensemble also has the largest signal along the northeastern coast but also suggests an additional contribution inland in the northern central Greenland-a pattern that is only seen in GISSH among the individual models. Compared to individual models, the larger ensemble in ALLCMIP tends to exhibit more widespread significant gradients on the more central parts of the ice sheet, although still more modest than along the coasts.

Observations are currently showing year-round retreat of sea ice in the BK region (Onarheim et al., 2018), and our study is not the first to find a link from BK ice loss to Greenland warming. Simulations with an atmosphere-only general circulation model by Screen (2017) indicate that BK ice loss, when acting as the only forcing, leads to wintertime (October-March) warming all over Greenland. The spatial pattern does, however, not resemble the strong coastal signal found by our linear framework. Using reanalysis data, Koenigk et al. (2016) find that the November sea ice area in the Barents Sea has a negative correlation with winter temperatures over Greenland. As the largest warming impact of ice loss occurs in winter (Vihma, 2014), these wintertime warming patterns will likely also have an impact on the annual mean warming.

Sea ice loss in the $\mathrm{CAB}$ region has a significant link to warming on the west coast in all the models, as evident from Figure 3. HadGEM and MPI indicate a limited impact, while CNRM, CSIRO, GISSR, and IPSL indicate that the sea ice contribution could be larger than that following the global warming on varying parts of the coast. Several models additionally indicate a more widespread but weak impact on the central ice sheet (ALLCMIP, BCC, CSIRO, EC-Earth, and IPSL) and some even on the east coast (CCSM4, CNRM, and GISSR). 


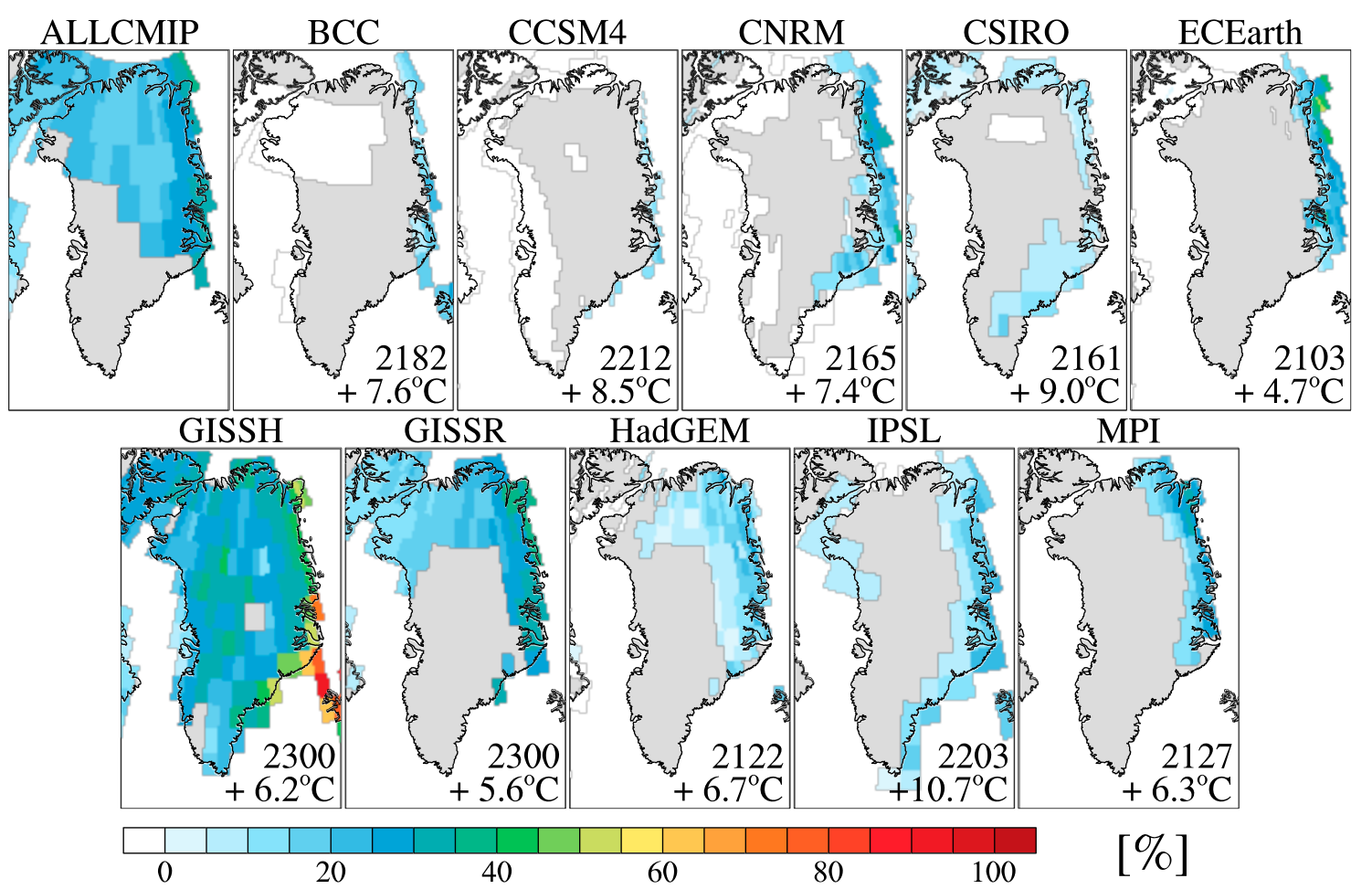

Figure 2. Linearized warming estimate attributed to sea ice loss in the Barents-Kara (BK) region (\%) calculated as the ratio of the warming from the linear relationship compared to that simulated in the model over the same period. Regressions are only calculated in grid cells within each model's land mask. Gray land areas indicate that the regression did not meet the statistical criteria, and white areas indicate $a_{\text {ice }}>0$. Numbers in the lower right-hand corner indicate the year of regional ice loss (top) and the global warming at that time (bottom) for each model.

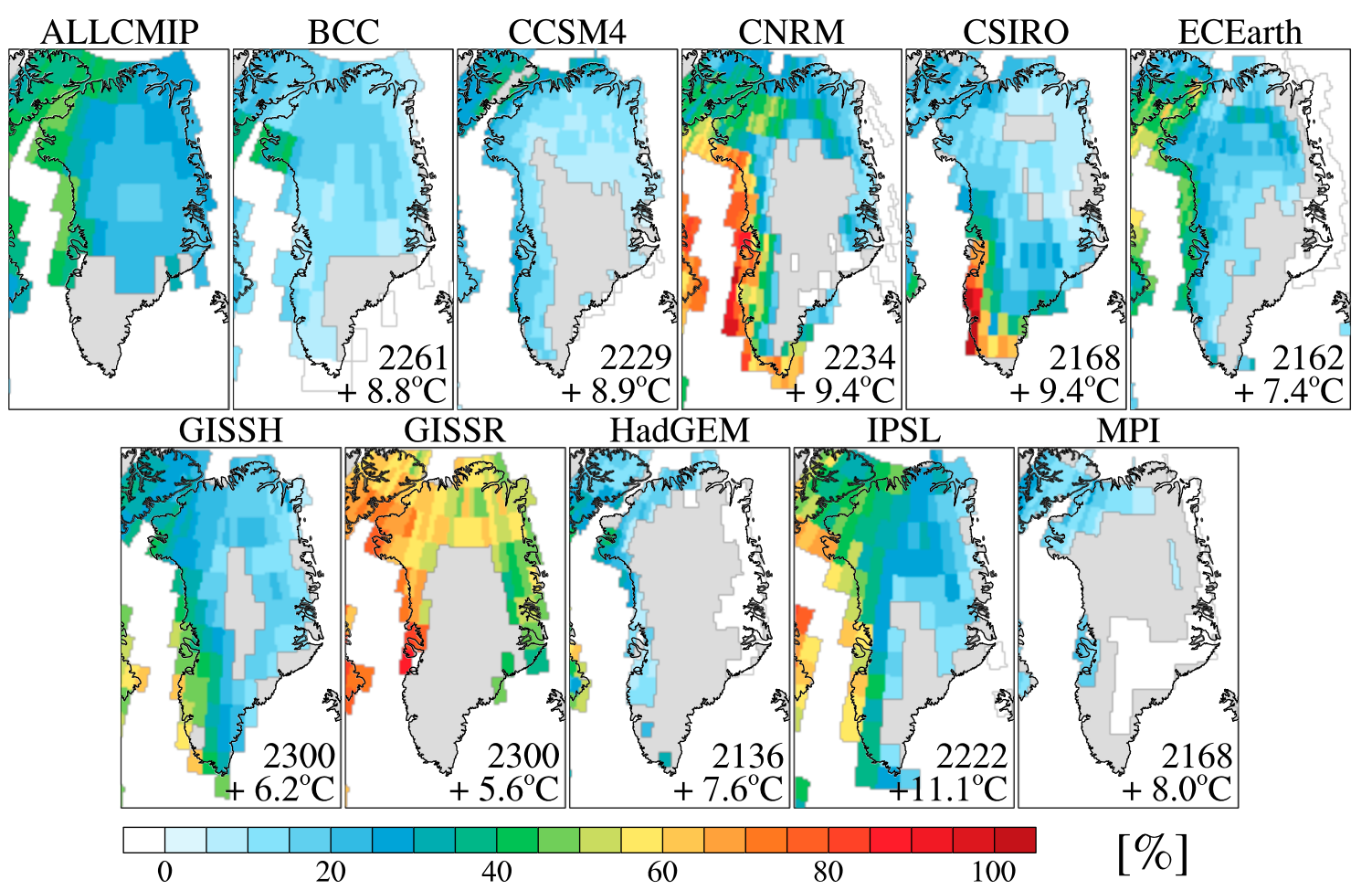

Figure 3. As Figure 2, but for the Canadian Archipelago and Baffin Bay sea ice region (CAB). 


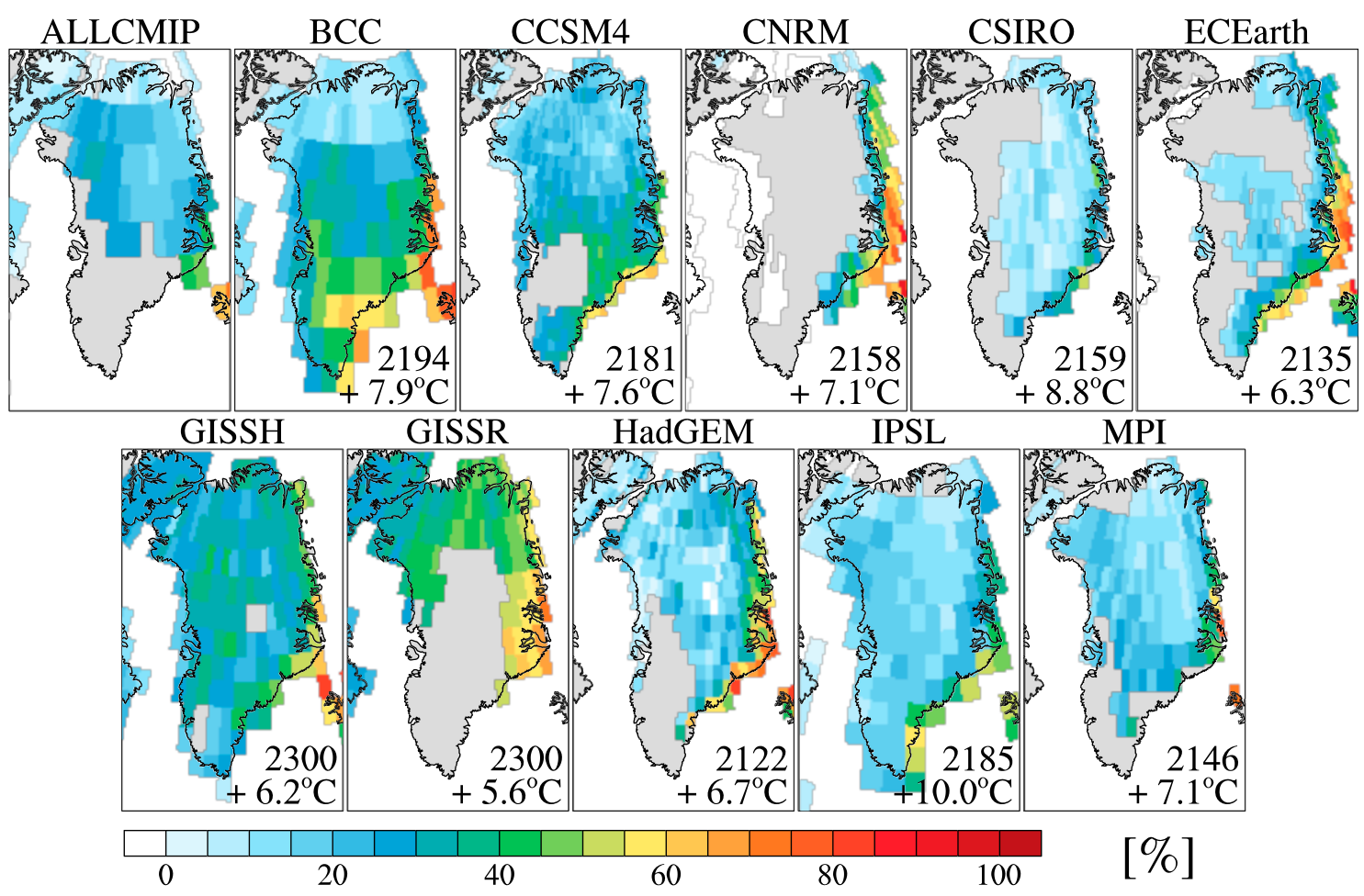

Figure 4. As Figure 2, but for the Greenland Sea (GS) region.

A wide range of approaches have previously indicated that Baffin Bay sea ice changes impact conditions on Greenland. Rennermalm et al. (2009) and Stroeve et al. (2017) present process-based analyses linking sea ice loss through changed surface fluxes to increased melt on GrIS. In agreement with the signals we see along the west coast (Figure 3), both of these studies find that sea ice loss in Baffin Bay promotes melting on the adjacent parts of the ice sheet. Similarly, Ballinger et al. (2018) show correlation between the freeze onset timing in the fall and the observed coastal temperature from September to December. Stronger and more widespread significant correlations are found on southwestern coastal areas. The link is further substantiated by the idealized model study by Screen (2017), which indicates a wintertime warming impact of $\mathrm{CAB}$ ice loss in the outermost area along the west coast, consistent with the strongest signal in our attribution.

The GS region stands out with a robust warming signature on the east coast in all the models (Figure 4). With a few exceptions (CNRM and GISSR) part of the signal on the central ice sheet can also be attributed to the GS sea ice changes. ALLCMIP has the strongest signal on the central east coast but also features a sizeable contribution on the northern part of central GrIS. While similar contributions are seen in individual models, all the models show a larger difference between the east coast and the central GrIS compared to ALLCMIP.

Ballinger et al. (2018) and Koenigk et al. (2016) both demonstrate links between the fall sea ice conditions in the Greenland Sea and the fall/winter temperature on the adjacent east coast. During summer, Rennermalm et al. (2009) also find local correlations between sea ice cover and GrIS melt on selected parts of the east coast. Atmospheric model studies (Merz et al., 2016; Screen, 2017) also show that GS ice loss causes warming on the eastern and southern parts of Greenland; Merz et al. (2016) even illustrate how GS ice loss may cause atmospheric circulation changes that causes substantial warming over Greenland (albeit under Last Interglacial climate conditions).

A general feature of our warming attribution is the apparently limited link between regional sea ice loss and warming on central GrIS. This may be explained by features of the Arctic atmospheric circulation. The lower Arctic atmosphere is very stably stratified with frequent inversions during winter (Serreze et al., 1992; Wexler, 1936), where the potential warming impact is at its maximum. The high stability limits the 
vertical extent of the warming (Vihma, 2014), which could contribute to keeping the surface-based warming from reaching the central, elevated part of GrIS. The warming from sea ice loss will, however, gradually weaken the stable stratification (Taylor et al., 2018; Vihma, 2014), meaning that this effect will diminish as the sea ice is lost. A second factor that may limit warming on central GrIS is downslope katabatic winds, which can inhibit heat advection toward the central ice sheet (Noël et al., 2014).

Despite these consistent dynamical arguments, earlier studies do indicate that atmospheric circulation changes can link sea ice loss to more widespread warming on GrIS (e.g., Knudsen et al., 2015; Liu et al., 2016). We speculate that these circulation-related patterns observed in relation to recent sea ice loss may not dominate in the long-term view or that they are not represented in our model ensemble.

A particular concern regarding warming on Greenland is the potential for increased melt on the ice sheet contributing to global sea level rise. Assessment of ice sheet changes, however, involves contributions from precipitation changes, surface processes, and ice dynamics and cannot be based solely on warming. Nevertheless, this concern merits a closer look at the seasonal differences and the trends during summer. In this linear framework, attribution of summertime warming is challenged by more limited warming during summer and by shorter time series of data (summer sea ice disappears several decades before winter sea ice). Furthermore, the temperature change may be highly nonlinear in the transition toward an ice-free Arctic, where summertime temperatures are no longer limited by melting snow and ice. These factors combined mean that the signals are less robust, but the spatial warming patterns for the highlighted regions (BK, $\mathrm{CAB}$, and GS) are similar when reproduced for warming and ice loss in the summer half year average (Figures S9-S11 show the results from regressions based on April-October averages of $\Delta T_{\mathrm{GrIS}}$ and sea ice area change). For peak summer conditions (June-August), the lengths of the time series become too short to obtain widespread significant signals, but a subset of the models does show weaker patterns reminiscent of Figures S9-S11 (not shown). The magnitude of warming attributable to sea ice loss is much lower during summer (the largest values are generally $<30 \%$ ) but still mainly found along the coasts adjacent to the ice loss. Note that wintertime warming will lead to a longer melting season, as the melting point can be reached earlier in the spring. This may not be reflected in the summer temperature near the ice sheet, which will be limited to the melting point as long as snow and ice are present.

The results from the alternate approach in equation (2) are qualitatively similar to those following equation (1). The spatial patterns of the warming contributions exhibit larger spatial variability, but the overall features described above are generally comparable (compare Figures 2-4 and Figures S12-S14). As expected, the magnitude of the LWE is more modest when using the residual sea ice areas. Together, the two methods in our linear framework thus suggest that the impact from sea ice loss is a minor contribution to warming on Greenland, which is mainly manifested in coastal areas in response to nearby ice loss.

We have repeated the analysis for reanalysis data from the satellite era 1979-2014 from ERA-Interim (Dee et al., 2011) downscaled to 5-km resolution using HIRHAM5 (Christensen et al., 2006; Langen et al., 2017; Lucas-Picher et al., 2012; not shown). These regressions do, however, not yield any widespread significant results (using our selected criteria of $R^{2}>0.9$ for the regression fit and $p>0.95$ for the gradients). The limited trends in annual mean sea ice cover in this period compared to the large interannual variability unfortunately inhibit any robust attribution with the current length of the observational record.

\section{Conclusions}

The aim of this study was to assess if part of the warming over Greenland can be attributed to sea ice changes in different parts of the Arctic. Using a multiple linear regression framework based on an ensemble of CMIP5 models, we separated the fraction of the simulated warming in each point on Greenland, which followed the variability of regional sea ice cover rather than that of the global warming. This allowed for a simple quantification of the warming contribution from sea ice loss and insight into the spatial pattern on Greenland that could be linked to sea ice changes in the different regions. The spatial patterns reveal that the impact of sea ice loss is largely confined to the coastal, lower elevation parts of Greenland. The most robust warming contributions are found for sea ice loss in regions adjacent to Greenland (BK, GS, and $\mathrm{CAB}$ ), with the largest amplitude on the coasts facing these regions. This finding is consistent with more process-based, dynamical studies. Sea ice changes in more distant parts appear to have limited impact on Greenland temperatures. 
Regarding the magnitude of warming, this linear framework indicates that the warming attributed to sea ice variability is a minor contribution compared to that following directly from global warming. Locally in coastal regions, it can, however, become a dominant signal. Finally, it should be noted that we have focused solely on the warming on Greenland. How this warming in conjunction with precipitation changes and ocean warming impacts the ice sheet mass balance and global sea level is beyond the scope of this study, but the framework could in principle be applied to melt or surface mass balance changes instead of temperature.

\section{Acknowledgments}

The authors thank Dr. Shuting Yang, Danish Meteorological Institute, for helpful discussion and for providing data from EC-Earth. We acknowledge the World Climate Research Program's Working Group on Coupled Modelling, which is responsible for CMIP, and we thank the climate modeling groups (Table S1) for producing and making available their model output. For CMIP the U.S. Department of Energy's Program for Climate Model Diagnosis and Intercomparison provides coordinating support and led development of software infrastructure in partnership with the Global Organization for Earth System Science Portals. The research leading to these results received funding from the European Research Council under the EU FP7/ERC Grant agreement 610055 as part of the ice2ice project. The authors further thank the Editor and an anonymous reviewer for their constructive comments on the manuscript.

\section{References}

Ballinger, T. J., Hanna, E., Hall, R. J., Miller, J., Ribergaard, M. H., \& Høyer, J. L. (2018). Greenland coastal air temperatures linked to Baffin Bay and Greenland Sea ice conditions during autumn through regional blocking patterns. Climate Dynamics, 50(1-2), 83-100. https:// doi.org/10.1007/s00382-017-3583-3

Bindoff, N. L., Stott, P. A., AchutaRao, K. M., Allen, M. R., Gillett, N., Gutzler, D., et al. (2013). Detection and attribution of climate change: from global to regional. In T. F. Stocker, D. Qin, G.-K. Plattner, M. Tignor, S. K. Allen, J. Boschung, A. Nauels, Y. Xia, V. Bex, \& P. M. Midgley (Eds.), Climate change 2013: The physical science basis. Contribution of Working Group I to the Fifth Assessment Report of the Intergovernmental Panel on Climate Change (867-952). Cambridge, United Kingdom and New York, NY, USA: Cambridge University Press.

Christensen, O. B., Drews, M., Christensen, J. H., Dethloff, K., Ketelsen, K., Hebestadt, I., \& Rinke, A. (2006). The HIRHAM regional climate model, version 5 (Technical Report No. 06-17). Danish Meteorological Institute, Copenhagen, Denmark.

Dai, A., Luo, D., Song, M., \& Liu, J. (2019). Arctic amplification is caused by sea-ice loss under increasing $\mathrm{CO}_{2}$. Nature Communications, 10(1). https://doi.org/10.1038/s41467-018-07954-9

Dee, D. P., Uppala, S. M., Simmons, A. J., Berrisford, P., Poli, P., Kobayashi, S., et al. (2011). The ERA-Interim reanalysis: Configuration and performance of the data assimilation system. Quarterly Journal of the Royal Meteorological Society, 137(656), 553-597. https://doi.org/ $10.1002 / \mathrm{qj} .828$

Flato, G., Marotzke, J., Abiodun, B., Braconnot, P., Chou, S. C., Collins, W., et al. (2013). Evaluation of climate models. In T. F. Stocker, D. Qin, G.-K. Plattner, M. Tignor, S. K. Allen, J. Boschung, A. Nauels, Y. Xia, V. Bex, \& P. M. Midgley (Eds.), Climate change 2013: The physical science basis. Contribution of Working Group I to the Fifth Assessment Report of the Intergovernmental Panel on Climate Change (741-866). Cambridge, United Kingdom and New York, NY, USA: Cambridge University Press.

Forster, P. M., Andrews, T., Good, P., Gregory, J. M., Jackson, L. S., \& Zelinka, M. (2013). Evaluating adjusted forcing and model spread for historical and future scenarios in the CMIP5 generation of climate models. Journal of Geophysical Research: Atmospheres, 118, 1139-1150. https://doi.org/10.1002/jgrd.50174

Hazeleger, W., Severijns, C., Semmler, T., Ştefănescu, S., Yang, S., Wang, X., et al. (2010). EC-Earth: A seamless Earth-system prediction approach in action. Bulletin of the American Meteorological Society, 91(10), 1357-1364. https://doi.org/10.1175/2010BAMS2877.1

Hazeleger, W., Wang, X., Severijns, C., Ştefănescu, S., Bintanja, R., Sterl, A., et al. (2012). EC-Earth V2.2: Description and validation of a new seamless Earth system prediction model. Climate Dynamics, 39(11), 2611-2629. https://doi.org/10.1007/s00382-011-1228-5

Hezel, P. J., Fichefet, T., \& Massonnet, F. (2014). Modeled Arctic sea ice evolution through 2300 in CMIP5 extended RCPs. The Cryosphere, 8(4), 1195-1204. https://doi.org/10.5194/tc-8-1195-2014

Knudsen, E. M., Orsolini, Y. J., Furevik, T., \& Hodges, K. I. (2015). Observed anomalous atmospheric patterns in summers of unusual Arctic sea ice melt. Journal of Geophysical Research: Atmospheres, 120, 2595-2611. https://doi.org/10.1002/2014JD022608

Koenigk, T., Caian, M., Nikulin, G., \& Schimanke, S. (2016). Regional Arctic sea ice variations as predictor for winter climate conditions. Climate Dynamics, 46(1-2), 317-337. https://doi.org/10.1007/s00382-015-2586-1

Langen, P. L., Fausto, R. S., Vandecrux, B., Mottram, R. H., \& Box, J. E. (2017). Liquid water flow and retention on the Greenland Ice Sheet in the regional climate model HIRHAM5: Local and large-scale impacts. Frontiers in Earth Science, 4. https://doi.org/10.3389/ feart.2016.00110

Larsen, J. N., Anisimov, O. A., Constable, A., Hollowed, A. B., Maynard, N., Prestrud, P., et al. (2014). Polar regions. In V. R. Barros, C. B. Field, D. J. Dokken, M. D. Mastrandrea, K. J. Mach, T. E. Bilir, M. Chatterjee, K. L. Ebi, Y. O. Estrada, R. C. Genova, B. Girma, E. S. Kissel, A. N. Levy, S. MacCracken, P. R. Mastrandrea, \& L. L. White (Eds.), Climate change 2014: Impacts, adaptation, and vulnerability. Part B: Regional aspects. Contribution of Working Group II to the Fifth Assessment Report of the Intergovernmental Panel on Climate Change, (pp. 1567-1612). Cambridge, United Kingdom and New York, NY, USA: Cambridge University Press.

Liu, J., Chen, Z., Francis, J., Song, M., Mote, T., \& Hu, Y. (2016). Has Arctic sea ice loss contributed to increased surface melting of the Greenland Ice Sheet? Journal of Climate, 29(9), 3373-3386. https://doi.org/10.1175/JCLI-D-15-0391.1

Lucas-Picher, P., Wulff-Nielsen, M., Christensen, J. H., Aðalgeirsdóttir, G., Mottram, R., \& Simonsen, S. B. (2012). Very high resolution regional climate model simulations over Greenland: Identifying added value. Journal of Geophysical Research, 117, D02108. https://doi. org/10.1029/2011JD016267

Massonnet, F., Fichefet, T., Goosse, H., Bitz, C. M., Philippon-Berthier, G., Holland, M. M., \& Barriat, P.-Y. (2012). Constraining projections of summer Arctic sea ice. The Cryosphere, 6(6), 1383-1394. https://doi.org/10.5194/tc-6-1383-2012

Meier, W. N., Hovelsrud, G. K., van Oort, B. E. H., Key, J. R., Kovacs, K. M., Michel, C., et al. (2014). Arctic sea ice in transformation: A review of recent observed changes and impacts on biology and human activity. Reviews of Geophysics, 52, 185-217. https://doi.org/ 10.1002/2013RG000431

Meinshausen, M., Smith, S. J., Calvin, K., Daniel, J. S., Kainuma, M. L. T., Lamarque, J.-F., et al. (2011). The RCP greenhouse gas concentrations and their extensions from 1765 to 2300. Climatic Change, 109(1-2), 213-241. https://doi.org/10.1007/s10584-011-0156-Z

Merz, N., Born, A., Raible, C. C., \& Stocker, T. F. (2016). Warm Greenland during the last interglacial: The role of regional changes in sea ice cover. Climate of the Past, 12(10), 2011-2031. https://doi.org/10.5194/cp-12-2011-2016

Mouginot, J., Rignot, E., Bjørk, A. A., van den Broeke, M., Millan, R., Morlighem, M., et al. (2019). Forty-six years of Greenland Ice Sheet mass balance from 1972 to 2018. Proc. Natl. Acad. Sci. 201904242.

Noël, B., Fettweis, X., van de Berg, W. J., van den Broeke, M. R., \& Erpicum, M. (2014). Sensitivity of Greenland Ice Sheet surface mass balance to perturbations in sea surface temperature and sea ice cover: A study with the regional climate model MAR. The Cryosphere, 8(5), 1871-1883. https://doi.org/10.5194/tc-8-1871-2014 
Notz, D., \& Stroeve, J. C. (2016). Observed Arctic sea-ice loss directly follows anthropogenic $\mathrm{CO}_{2}$ emission. Science, 354(6313), 747-750. https://doi.org/10.1126/science.aag2345

Onarheim, I. H., Eldevik, T., Smedsrud, L. H., \& Stroeve, J. C. (2018). Seasonal and regional manifestation of Arctic sea ice loss. Journal of Climate, 31(12), 4917-4932. https://doi.org/10.1175/JCLI-D-17-0427.1

Overland, J. E., Dethloff, K., Francis, J. A., Hall, R. J., Hanna, E., Kim, S.-J., et al. (2016). Nonlinear response of mid-latitude weather to the changing Arctic. Nature Climate Change, 6(11), 992-999. https://doi.org/10.1038/nclimate3121

Pedersen, R. A., Cvijanovic, I., Langen, P. L., \& Vinther, B. M. (2016). The impact of regional Arctic sea ice loss on atmospheric circulation and the NAO. Journal of Climate, 29(2), 889-902. https://doi.org/10.1175/JCLI-D-15-0315.1

Pithan, F., \& Mauritsen, T. (2014). Arctic amplification dominated by temperature feedbacks in contemporary climate models. Nature Geoscience, 7(3), 181-184. https://doi.org/10.1038/NGEO2071

Rennermalm, A. K., Smith, L. C., Stroeve, J. C., \& Chu, V. W. (2009). Does sea ice influence Greenland ice sheet surface-melt? Environmental Research Letters, 4(2), 024011. https://doi.org/10.1088/1748-9326/4/2/024011

Screen, J. A. (2017). Simulated atmospheric response to regional and Pan-Arctic sea ice loss. Journal of Climate, 30(11), 3945-3962. https:// doi.org/10.1175/JCLI-D-16-0197.1

Screen, J. A., \& Simmonds, I. (2010). The central role of diminishing sea ice in recent Arctic temperature amplification. Nature, 464(7293), 1334-1337. https://doi.org/10.1038/nature09051

Serreze, M. C., Barrett, A. P., \& Cassano, J. J. (2011). Circulation and surface controls on the lower tropospheric air temperature field of the Arctic. Journal of Geophysical Research, 116(D7). https://doi.org/10.1029/2010JD015127

Serreze, M. C., Barrett, A. P., Stroeve, J. C., Kindig, D. N., \& Holland, M. M. (2009). The emergence of surface-based Arctic amplification The Cryosphere, 3(1), 11-19. https://doi.org/10.5194/tc-3-11-2009

Serreze, M. C., \& Barry, R. G. (2011). Processes and impacts of Arctic amplification: A research synthesis. Global and Planetary Change, 77(1-2), 85-96. https://doi.org/10.1016/j.gloplacha.2011.03.004

Serreze, M. C., Schnell, R. C., \& Kahl, J. D. (1992). Low-level temperature inversions of the Eurasian Arctic and comparisons with soviet drifting station data. Journal of Climate, 5(6), 615-629. https://doi.org/10.1175/1520-0442(1992)005<0615:LLTIOT>2.0.CO;2

Stroeve, J. C., Mioduszewski, J. R., Rennermalm, A., Boisvert, L. N., Tedesco, M., \& Robinson, D. (2017). Investigating the local-scale influence of sea ice on Greenland surface melt. The Cryosphere, 11(5), 2363-2381. https://doi.org/10.5194/tc-11-2363-2017

Stroeve, J. C., Serreze, M. C., Holland, M. M., Kay, J. E., Malanik, J., \& Barrett, A. P. (2012). The Arctic's rapidly shrinking sea ice cover: A research synthesis. Climatic Change, 110(3-4), 1005-1027. https://doi.org/10.1007/s10584-011-0101-1

Sun, L., Deser, C., \& Tomas, R. A. (2015). Mechanisms of stratospheric and tropospheric circulation response to projected Arctic sea ice loss. Journal of Climate, 28(19), 7824-7845. https://doi.org/10.1175/JCLI-D-15-0169.1

Taylor, K. E., Stouffer, R. J., \& Meehl, G. A. (2012). An overview of CMIP5 and the experiment design. Bulletin of the American Meteorological Society, 93(4), 485-498. https://doi.org/10.1175/BAMS-D-11-00094.1

Taylor, P., Hegyi, B., Boeke, R., \& Boisvert, L. (2018). On the increasing importance of air-sea exchanges in a thawing Arctic: A review. Atmosphere, 9(2), 41. https://doi.org/10.3390/atmos9020041

Trusel, L. D., Das, S. B., Osman, M. B., Evans, M. J., Smith, B. E., Fettweis, X., et al. (2018). Nonlinear rise in Greenland runoff in response to post-industrial Arctic warming. Nature, 564(7734), 104-108. https://doi.org/10.1038/s41586-018-0752-4

van Vuuren, D. P., Edmonds, J., Kainuma, M., Riahi, K., Thomson, A., Hibbard, K., et al. (2011). The representative concentration pathways: An overview. Climatic Change, 109(1-2), 5-31. https://doi.org/10.1007/s10584-011-0148-z

Vihma, T. (2014). Effects of Arctic sea ice decline on weather and climate: A review. Surveys in Geophysics, 35(5), 1175-1214. https://doi. org/10.1007/s10712-014-9284-0

von Storch, H., \& Zwiers, F. W. (2001). Statistical analysis in climate research. Cambridge: Cambridge University Press.

Wang, M., \& Overland, J. E. (2012). A sea ice free summer Arctic within 30 years: An update from CMIP5 models. Geophysical Research Letters, 39, L18501. https://doi.org/10.1029/2012GL052868

Wexler, H. (1936). Cooling in the lower atmosphere and the structure of polar continental air. Monthly Weather Review, 64(4), 122-136. https://doi.org/10.1175/1520-0493(1936)64<122:CITLAA $>2.0 . C O ; 2$ 